\title{
Dysfunctional Organization: The Leadership Factor
}

\author{
Daniel S. Alemu \\ The Sage Colleges, Troy, NY, USA \\ Email: alemud@sage.edu
}

Received 28 December 2015; accepted 4 March 2016; published 7 March 2016

Copyright (C) 2016 by author and Scientific Research Publishing Inc.

This work is licensed under the Creative Commons Attribution International License (CC BY). http://creativecommons.org/licenses/by/4.0/

(c) (i) Open Access

\begin{abstract}
In an extension of studies on dysfunctional organizations, vis-à-vis leadership, the current research examines leaders of dysfunctional and functional organizations in view of the functions of leadership. Sixteen variables related to leadership functions were tested to examine the relationship between leadership and organizational level of functionality and the differences between the characteristics of leaders of functional and dysfunctional organizations. A strong positive correlation was found between effective leadership and organizational level of functionality and a statistically significant difference was found between the characteristics of leaders of functional and dysfunctional organizations.
\end{abstract}

\section{Keywords}

Dysfunctional Organization, Dysfunctional Leadership, Leadership

\section{Overview of Literature on Dysfunctional Organization}

Numerous researches on dysfunctional organization explored the issue using different variables and various approaches. Reviewing the literature on dysfunctional organizations deeper, one can quickly understand that the issue has been explored in relation to individual behaviors in work place (Denenberg \& Braverman, 1999; Griffin \& Lopez as cited in Van Fleet and Griffin 2006; Griffin \& O’Leary-Kelly, 2004); organizational factors (Balthazard, Cook, \& Potter, 2006; Chatman \& Jehn, 1994; Gerstner, 2002; Javidan, 2001; Weber, Shenkar, \& Raveh, 1996); and the role of the leader on organizational dynamics (Burton, 2002; Caldwell \& Canuto-Carranco, 2010; Harvey, Martinko \& Douglas, 2006; Kellerman, 2004; Ouimet, 2010; Van Fleet \& Griffin, 2006).

Studies that focus on individual behavior suggest that organizational dysfunction is the result of dysfunctional behavior of individuals as displayed in organizational settings. Some of these studies focus on specific genetic predispositions, personality factors, and social background of individuals in relation to violence or behavioral 
problems as they affect the work environment (Denenberg \& Braverman, 1999; Griffin \& Lopez as cited in Van Fleet and Griffin, 2006; Griffin \& O’Leary-Kelly, 2004). Other studies provide a more generalized picture of the negative implications of individuals' "counterproductive behaviors” on organizational functions (Levine, 2010; Toffler \& Raingold, 2003). Both of these research strands focus on what individuals with behavioral issues contribute to organizational dysfunctions. Organizations will always have such individuals and organizational dysfunctions may occur even in organizations that are free of individual workplace behavioral issues. While individuals with behavioral issues are difficult to work with, the sole impact of such behaviors on organizational dysfunction needs a deeper look.

The other widely studied variable in relation to dysfunctional organization is organizational culture. Organizational culture studies often focus on the role organizations play by way of accepting or promoting certain values in conducting business that encourage or discourage the display of certain behavior and the manner work is done. Balthazard, Cook and Potter (2006) draw similarities between dysfunctional organizations and dysfunctional individuals arguing that both are affected more by internal factors than external ones. Balthzarard, Cook and Potter contend that culture plays a pivotal internal organizational factor in how organizations function. Similarly, organizational culture is depicted by many as what literally makes or breaks an organization (Chatman \& Jehn, 1994; Gerstner, 2002; Javidan, 2001; Weber, Shenkar, \& Raveh, 1996).

Linking organizational culture and individual behaviors further, Griffin and Lopez (as cited in Van Fleet and Griffin, 2006: p. 704) provided a model that depicts the relationship between "individual predisposition for dysfunctional behavior" and "organizational propensity to elicit dysfunctional behavior." In this model, they explain that, when individuals in an organization have high predisposition for dysfunctional behavior and the organization in which they work is of high propensity to elicit dysfunctional behavior, then the result will be high incidences of dysfunctional behavior at workplace.

With intentions ranging from simply understanding internal organizational culture to pinpointing problems organizations face, there has been a great deal of interest among organizations to conduct organizational selfstudy or using external reviewers that often focuses on assessing culture. Survey instruments and interview protocols have been developed and used to understand organizational culture. The Organizational Culture Inventory (OCI), for example, is an example of such instruments that has been translated in many languages and widely used around the world (Balthazard, Cook, \& Potter, 2006). Despite such interest and attempt, understanding organizational culture does not necessarily equate to understanding issues related to organizational dysfunction. While the culture of organizations may play a role in the overall function/dysfunction of an organization, the level of its contribution needs further investigation.

The other widely studied subject in relation to organizational dysfunction is leadership. Leaders play critical roles in shaping organizational directions (vision), crafting organizational strategies, influencing stakeholders, and ultimately materializing organizational goals. This unique position makes leaders to be an important variable in organizational dynamics.

In recent decades, there has been a growing interest among researchers in the area of dysfunctional organizations in relation to leadership. Several articles touched the direct or indirect roles of the leader to organizational dysfunction (Burton, 2002; Caldwell \& Canuto-Carranco, 2010; Harvey, Martinko, \& Douglas, 2006; Kellerman, 2004; Ouimet, 2010; Van Fleet \& Griffin, 2006).

Focusing on the behavior of leaders in relation to organizational dysfunction, Caldwell and Canuto-Carranco (2010) illustrate a type of dysfunctional leadership where leaders disrespect, abuse and mistreat organizational members. Caldwell and Canuto-Carranco suggest that in the guise of organizational effectiveness and promoting productivity, some leaders often abuse their power and create unhealthy culture to which employees react negatively and thereby promoting organizational dysfunction. This corroborated a research by Tepper, Henle, Lambert, Giacalone, and Duffy (2008) that found abused employees to be less committed to organizational goal achievement, hence contributing to organizational dysfunctions. Similarly, Burton (2002) suggested that leaders who displayed threatening behaviors, harassment, bullying and physical assault of co-workers created a dysfunctional organizational climate. Abusive leaders, Caldwell and Canuto-Carranco (2010, p. 168), further argued, "are not worthy to lead."

Ouimet (2010) specifically studied leaders' narcissistic behavior which he categorized as a "dysfunctional form of leadership" (p. 713). According to the author, narcissistic leaders are individuals focused more on selfglorification rather than serving the organization. Thus, he contends, it is not in the best interest of any organization to have such individuals in its helm.

Focusing on the actions and inactions of leaders, Harvey, Martinko and Douglas (2006) underline the contri- 
bution of the leader for organizational function or dysfunction based on "responses to workplace outcome" (p. 748). Utilizing "Attribution Theory", they suggest that "dysfunctional leaders are frequently driven by biased causal perceptions; creating a situation in which conflict, neglect emotions, and unproductive behaviors are likely" (p. 748). On the other hand, they suggest, "functional leaders create situations in which the negative influences of attributional biases on leader-member relationships is minimized" (p. 748).

Stressing on the importance of the modeling role of the leader in encouraging or discouraging dysfunctional organizational culture, Van Fleet and Griffin (2006) underline that "if a top manager is commonly known to be untruthful, if a leader does not respect the rights of others, if a leader puts profit before all else, others will likely recognize the signal” (p. 704).

"Dysfunctional" is a self-explanatory adjective. When it is used to describe leadership, it does not only tell about how bad the leader is, it portrays a dreadful picture of the entire organization. Literature on the issue of dysfunctional leadership shows this not-so-nice picture in a vivid and unforgiving manner. Dandira (2012) equates dysfunctional leadership to "organizational cancer." Caldwell and Canuto-Carranco (2010) described dysfunctional leaders as "organizational terrorists." Authors like Ouimet (2010) emphasize in the behavioral issues to connect dysfunctional leadership with "narcissism." Goldman (2006) labels extreme case of dysfunctional leadership as "high toxicity leadership."

In sum, the literature on the issue of dysfunctional leadership predominantly approaches dysfunction from symptom-focused framework. The emphasis, in particular, has been on ill behaviors and wrongdoings of individual leaders and followers as signs of dysfunction there by concluding how such behaviors or practices result in dysfunctional organization. In the present research, dysfunction is considered in its literary meaning of impaired function rather than its symptoms. One way of understanding whether leadership is dysfunctional or not is by examining leadership practices in view of the characteristics of functional leadership. By so doing, this research provides a different way on how we look at and understand dysfunctions. In this study, sixteen variables related to leadership were tested to examine dysfunctional leadership.

\section{Methodology and Results}

This quantitative study examines organizational dysfunction in relation to leadership. Participants initially rated an organization they were knowledgeable about (e.g., former or current organization) on a nine point Likertscale where 1 was 'extremely dysfunctional' and 9 was 'very well-functioning'. Then they were asked to rate the same organization on their agreement of 16 leadership characteristic statements in a 9 level Likert-scale where 1 is "not at all descriptive" and 9 is "very descriptive".

Three research questions guided this research. Research question one investigated the extent of the relationship between leadership characteristics and organizational level of functionality. Research question two focused on the impact of leadership on organizational dysfunction. The last research question examined the difference between leaders of dysfunctional and functional organizations when specific leadership characteristics are considered. Data were analyzed using correlation, regression, and independent sample t-test respectively.

\subsection{Participants of the Study}

Participants for the study were selected through what is known as snowball sampling. Vogt and Johnson (2011) state that snowball sampling is "especially useful technique when the researcher wants to contact people with unusual experiences or characteristics who are likely to know one another" (p.368). The researcher considered it risky for employees to rate their current organization as dysfunctional or to rate their current leadership negatively. To avoid this, rather than studying specific organizations, the researcher used his social media contacts as initial participants to fill the online questionnaire and encouraged each contact to invite others in their circle to do the same, thereby creating a snowball sample. However, to be able to filter the responses at the end, the researcher included some general background questions in the survey such as the nature of their organizations (for profit, not-for-profit, and government), their educational and work experience, and their gender. Also, participation was limited to individuals who live in the United States.

A total of 185 individuals completed the questionnaire of which 97(52.4\%) were female, 80(43.2\%) were male, and $8(4.3 \%)$ did not identify their gender. Over a third (36.8\%) work for the government (local, state, or federal levels), 60(32.4\%) are employed by for profit organizations (small business or corporations), and 57(30.8) work for non-profit/non-governmental organizations (such as charities, foundations, community-based organizations, professional associations). The participants' levels of education range from high school to ter- 
minal degree completion. Of the total participants, 52(28\%) hold doctoral/terminal degree, 77(41.6\%) have masters degree, 38(20.5\%) completed undergraduate degree, $9(4.9 \%)$ have associate degree, the rest $9(4.9 \%)$ either have high school diploma or chose not to identify their level of education. The overwhelming majority, $147(79.5 \%)$ have 11 or more years of work experience, $26(14.1 \%)$ have six to ten years of experience and 6(3.2\%) worked for less than 5 years.

\subsection{Instrumentation}

The questionnaire/data collection instrument used for this study was created by the researcher. The items were carefully constructed based on the researcher's understanding of the functions and attributes of a leader in his study of the large body of leadership literature and his experience as a leader, as a member (follower), and as an observer of others' leadership. The instrument was found to be reliable with a Cronbach's alpha level of $\alpha=.97$ for its internal consistency. Alpha level of .7 or above is considered acceptable and a level $>.9$ is considered excellent/very high. When the internal consistency of an instrument is acceptable or high, it tells that the items (in this case the 16 items of the questionnaire) measure the same construct (leadership).

\subsection{Results}

The present study first examined the extent of relationship between the sixteen leadership characteristics and the level of organizational functionality. Correlation analysis was conducted to investigate the level of relations if any. As seen in Table 1, all sixteen leadership characteristics show moderate to strong positive correlation values $(r)$ between .487 and $.723(p \leq .01)$. This means those leaders that are rated higher in the sixteen leadership variables lead highly functioning organizations and those individuals that are rated low in the sixteen leadership variables lead dysfunctional organizations. Thus, there is a positive correlation between leadership characteristics and organizational functions.

Table 1. Correlation between Leadership characteristics and level of organizational functionality.

\begin{tabular}{|c|c|}
\hline & Organization functionality \\
\hline a. The Leader is genuine and truly devoted to the organization's goals/cause & $.613^{* *}$ \\
\hline $\begin{array}{l}\text { b. The Leader has a comprehensive knowledge about the organization and its functions } \\
\text { (s/he is well informed and understands trends and new technologies appropriate to the field) }\end{array}$ & $.619 * *$ \\
\hline c. The leader has rich leadership experience & $.674 * *$ \\
\hline d. The leader has rich job experience relevant to the organization & $.574 * *$ \\
\hline $\begin{array}{l}\text { e. The leader understands well the overall environment (political, social, economic) } \\
\text { and the community in which the organization operates }\end{array}$ & $.550 * *$ \\
\hline $\begin{array}{l}\text { f. The leader often exhibits good judgment in the timing and appropriateness of } \\
\text { critical decisions/actions needed. }\end{array}$ & $.721 * *$ \\
\hline g. The leader is skillful in working with people (all stakeholders) & $.688 * *$ \\
\hline h. The leader is visionary & $.629 * *$ \\
\hline i. The leader is persistent/tenacious even at tough times & $.492^{* *}$ \\
\hline $\begin{array}{l}\text { j. The leader does not usually seek spotlight rather acknowledges team efforts. } \\
\text { S/he prefers to serve than to be served. }\end{array}$ & $.497 * *$ \\
\hline k. Under his/her leadership the organization has been consistently meeting the goals set. & $.723^{* *}$ \\
\hline 1. The leader is willing to learn or to change when situations demand & $.688^{* *}$ \\
\hline m. The leader practices what he/she preaches and is a good role model & $.644^{* *}$ \\
\hline n. The leader motivates and cultivates others to grow as leaders & $.675^{* *}$ \\
\hline o. The Leader Meets Ethical expectation required by the position/job & $.487 * *$ \\
\hline p. The leader usually brings unique and productive insight in discussions and problem solving strategies & $.666^{* *}$ \\
\hline
\end{tabular}

**. Correlation is significant at the .01 level (2-tailed). 
Once the relationship between leadership characteristics was established, the next logical question was to further explore the impact of those leadership characteristics on the function of the organizations. Multiple regression analysis was conducted to examine the impact. Accordingly, the model summary of the regression analysis (Table 2) shows an $\mathrm{R}^{2}$ of .626. This means the model explain $62.6 \%$ of variability on organizational functionality due to the sixteen leadership characteristics. In other words $62.6 \%$ of the change in organizational function or dysfunction can be explained by leadership characteristics.

Further investigation of the coefficient table (Table 3) shows four of the sixteen leadership variables to have a statistically significant level $(p<.05)$ of impact. These variables included: 1$)$ the leader's "good judgment in the timing and appropriateness of critical decisions/actions needed"; 2) his/her leadership of the organization in "consistently meeting the goals set"; 3) the leader's practice of "what he/she preaches" as a good role model"; and 4) "the leader meets ethical expectation required by the position/job". In other words, these four variables are what are commonly referred in leadership literature, respectively, as: Decision Making, Goal achievement, Modeling, and Ethics.

Finally, this research investigated if there is any difference between leaders of functional and dysfunctional organizations in these four variables (Decision Making, Goal Achievements, Modeling, and Ethics). Independent Sample T-test analysis was conducted to see if there is a mean difference between the leaders of the two types of organizations in the four variables. Table 4 shows a clear mean difference between the two group in all the four variables. Meaning, leaders of dysfunctional organizations were rated with lower mean values in all the four variables (Decision Making, Goal Achievement, Modeling, and Ethics) while leaders of the very well-functioning organizations were all rated high in all variables with a significance value of $p<.001$.

Table 2. Regression model summary.

\begin{tabular}{ccccc}
\hline Model & $\mathrm{R}$ & $\mathrm{R}$ Square & Adjusted R Square & Std. Error of the Estimate \\
\hline 1 & $.791^{\mathrm{a}}$ & .626 & .578 & 1.451 \\
\hline
\end{tabular}

Table 3. Regression coefficient table.

\begin{tabular}{|c|c|}
\hline Leadership characteristics & Sig. \\
\hline a. The leader is genuine and truly devoted to the organization's goals/cause & .086 \\
\hline $\begin{array}{l}\text { b. The leader has a comprehensive knowledge about the organization and its functions } \\
\text { (s/he is well informed and understands trends and new technologies appropriate to the field) }\end{array}$ & .748 \\
\hline c. The leader has rich leadership experience & .120 \\
\hline d. The leader has rich job experience relevant to the organization & .298 \\
\hline $\begin{array}{l}\text { e. The leader understands well the overall environment (political, social, economic) } \\
\text { and the community in which the organization operates }\end{array}$ & .561 \\
\hline f. The leader often exhibits good judgment in the timing and appropriateness of critical decisions /actions needed & $.043^{*}$ \\
\hline g. The leader is skillful in working with people (all stakeholders) & .540 \\
\hline h. The leader is visionary & .609 \\
\hline i. The leader is persistent/tenacious even at tough times & .168 \\
\hline j. The leader does not usually seek spotlight rather acknowledges team efforts. S/he prefers to serve than to be served & .279 \\
\hline k. Under his/her leadership the organization has been consistently meeting the goals set & $.006{ }^{*}$ \\
\hline 1. The leader is willing to learn or to change when situations demand & .164 \\
\hline m. The leader practices what he/she preaches and is a good role model & $.031^{*}$ \\
\hline n. The leader motivates and cultivates others to grow as leaders & .309 \\
\hline o. The Leader Meets Ethical expectation required by the position/job & $.033^{*}$ \\
\hline p. The leader usually brings unique and productive insight in discussions and problem solving strategies & .133 \\
\hline
\end{tabular}

Dependent Variable: So how would do you rate "X" as an organization in a scale of 1 to 9 where: 1 = extremely dysfunctional, $9=$ very well functioning. 
Table 4. Mean difference between leadership characteristics of dysfunctional and very-well-functioning organizations.

\begin{tabular}{lccc}
\hline Leadership characteristics & $\begin{array}{c}\text { Leaders of dysfunctional } \\
\text { organizations }\end{array}$ & $\begin{array}{c}\text { Leaders of very well } \\
\text { functioning organizations }\end{array}$ & Sig. \\
\hline $\begin{array}{l}\text { The leader often exhibits good judgment in the timing } \\
\text { and appropriateness of critical decisions/actions needed. } \\
\text { (Decision Making) }\end{array}$ & 3.36 & 7.18 & $.000^{*}$ \\
$\begin{array}{l}\text { Under his/her leadership the organization has been } \\
\text { consistently meeting the goals set. (Goal Achievement) }\end{array}$ & 3.20 & 6.93 & $.000^{*}$ \\
$\begin{array}{l}\text { The leader practices what he/she preaches and is a good } \\
\text { role model. (Modeling) } \\
\begin{array}{l}\text { The Leader Meets Ethical expectation required by the } \\
\text { position/job. (Ethics) }\end{array}\end{array}$ & 3.22 & 6.83 & $.000^{*}$ \\
\hline
\end{tabular}

$P<.005^{*}$.

\section{Conclusion and Implications}

Leadership is a critical position for any organization. Not surprisingly, leaders are expected to deliver much. The question is, what do we really expect them to be and to do as they lead? This research focused on leadership as it relates to organizational dysfunction.

The body of research regarding leadership in relation to dysfunctional organizations has been scattered though not so scant. It can be summarized into four major thematic areas. The first theme has to do with personality disorder. These studies vary from specific issues as narcissistic behavior of leaders to their problematic genetic dispositions (Denenberg \& Braverman, 1999; Griffin \& Lopez, 2004; Griffin \& O’Leary-Kelly, 2004; Ouimet, 2010).

The second theme focuses on dysfunctional leadership as it relates on Ethical issues. Literature in this area focuses on immoral and illegal involvement of leaders as it affects the overall organizational work environment (Proyer, Oyler, \& Odom, 2013).

The third theme is Abuse of Power. This theme emphasizes on leaders that use their positional authority to terrorize (Caldwell \& Canuto-Carranco, 2010), bully, and harass (Burton, 2002) organizational members there by contributing to bad organizational climate.

The fourth theme focuses on Neglect. It emphasizes on leaders who do not pay appropriate attention to or ignore serious workplace issues thereby contributing to organizational dysfunction (Harvey, Martinko, \& Douglas, 2006).

This study took a different approach. Rather than starting from specific problems and practices of leaders and looking into how they affect organizational function, it started with a list of conventional leadership characteristics to see how the leaders deliver as leaders and how that affect organizational function/dysfunction. Several findings have been unearthed through the process. First, there is a strong positive correlation between leadership and organizational functionality. Meaning leaders of dysfunctional organizations exhibit poor leadership while leaders of highly functioning organizations show good leadership. Second, the impact of leadership to organizational function/dysfunction has been found to be significant. Of the sixteen leadership characteristics variables, however, four characteristics (decision making, goal achievement, modeling, and ethics) were found to have statistically significant impact. Looking further into these four variables, the data provided clear distinctions where leaders of functional organizations were rated high (very effective) and leaders of dysfunctional organizations were rated low (very ineffective).

This research has some practical implications for individual leaders. It is imperative that leaders reflect on their leadership from time to time. The four variables, namely, decision making, organizational goal achievement, modeling, and meeting ethical expectations were found to be critical leadership characteristics that distinguish leaders of functional organizations from those leading dysfunctional organizations. These variables could serve as starting points for self-reflections through asking such questions as: 'How does the way decision is made in the organization affect the way the organization functions? Is the organization achieving the intended goal? If not, why? How am I modeling as a leader? Are there any ethical issues that need to be addressed?

Organizations are complex and many variables interplay to result in organizational dysfunctions. This study is limited to the role of the leader in this complex dynamics. Still, the result shows that leadership matters in a sig- 
nificant way. Effective leaders influence groups through modeling and demonstrating exemplary ethical behavior. They are also engaged in making critical decisions, in a daily basis, as they lead toward organizational goal achievement. Seriously looking into these four leadership variables may benefit organizations in their efforts of addressing organizational dysfunctions.

\section{References}

Balthazard, P. A., Cooke, R. A., \& Potter, R. E. (2006). Dysfunctional Culture, Dysfunctional Organization: Capturing the Behavioral Norms That Form Organizational Culture and Drive Performance. Journal of Managerial Psychology, 21, 709732. http://dx.doi.org/10.1108/02683940610713253

Burton, J. (2002). The Leadership Factor: Management Practices Can Make Employees Sick. Accident Prevention, 22-26.

Caldwell, C., \& Canuto-Carranco, M. (2010). “Organizational Terrorism” and Moral Choices Exercising Voice When the Leader Is the Problem. Journal of Business Ethics, 97, 159-171. http://dx.doi.org/10.1007/s10551-010-0502-5

Chatman, J. A., \& Jehn, K. A. (1994). Assessing the Relationship between Industry Characteristics and Organizational Characteristics: How Different Can You Be? Academy of Management Journal, 37, 522-553. http://dx.doi.org/10.2307/256699

Dandira, M. (2012). Dysfunctional Leadership: Organizational Cancer. Business Strategy Series, 13, 188. http://dx.doi.org/10.1108/17515631211246267

Denenberg, R. V., \& Braverman, M. (1999). The Violence Prone Workplace. Ithaca, NY: Cornell University Press.

Gerstner, Jr., L. V. (2002). Who Says Elephants Can’t Dance? New York, NY: HarperCollins Publishers.

Goldman, A. (2006). High Toxicity Leadership Borderline Personality Disorder and the Dysfunctional Organization. Journal of Managerial Psychology, 21, 733-746. http://dx.doi.org/10.1108/02683940610713262

Griffin, R. W., \& O’Leary-Kelly, A. M. (2004). The Dark Side of Organizational Behavior. New York: Wiley.

Harvey, P., Martinko, M. J., \& Douglas, S. C. (2006). Causal Reasoning in Dysfunctional Leader-Member Interactions. Journal of Managerial Psychology, 21, 747-762. http://dx.doi.org/10.1108/02683940610713271

Javidan, M. (2001). The Impact of National Culture on Cross-Border Mergers: The Lessons from GLOBE. Paper: The 5th International Management Conference of the Carnegie Bosch Institute for Applied Studies. Berlin: Germany.

Kellerman, B. (2004). Bad Leadership: What It Is, How It Happens, Why It Matters. Boston: Harvard Business School Press.

Ouimet, G. (2010). Dynamics of Narcissistic Leadership in Organizations: Towards an Integrated Research Model. Journal of Managerial Psychology, 25, 713-726. http://dx.doi.org/10.1108/02683941011075265

Proyer, M. G., Oyler. J. D., \& Odom, R. Y. (2013). Out-of-Control Executives: What Trumps Smart? Journal of Management Policy and Practice, 14, 11-18.

Tepper, B. J., Henle, C. A., Lambert, L. S., Giacalone, R. A., \& Duffy, M. K. (2008). Abusive Supervision and Subordinates’ Organization Deviance. Journal of Applied Psychology, 93, 721-732. http://dx.doi.org/10.1037/0021-9010.93.4.721

Toffler, J. R. (2003). Final Accounting: Ambition, Greed and the Fall of Arthur Andersen. New York: Broadway Books.

Van Fleet, D. D., \& Griffin, R. W. (2006). Dysfunctional Organization Culture: The Role of Leadership in Motivating Dysfunctional Work Behaviors. Journal of Managerial Psychology, 21, 698-708.

http://dx.doi.org/10.1108/02683940610713244

Vogt, P., \& Johnson, B. (2011). Dictionary of Statistics and Methodology. London: Sage.

Weber, Y., Shenkar, O., \& Raveh, A. (1996). National and Corporate Cultural Fit in Mergers/Acquisitions: An Exploratory Study. Management Science, 42, 1215-1227. http://dx.doi.org/10.1287/mnsc.42.8.1215 